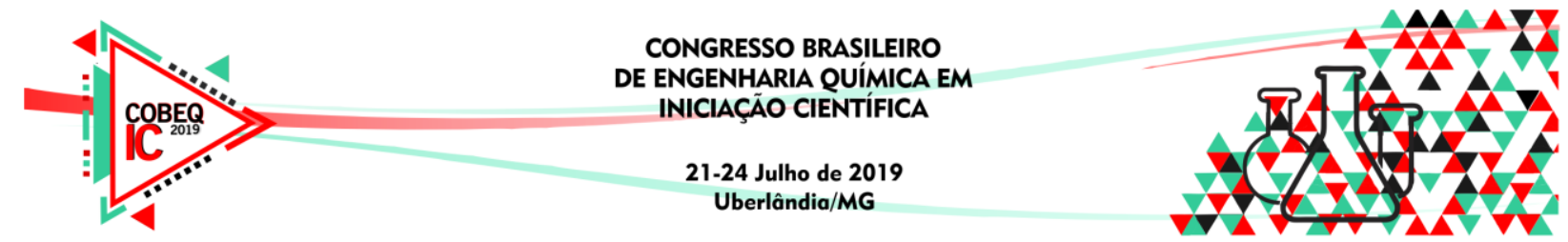

\title{
EXTRAÇÃO DO AMIDO PRESENTE NO REJEITO DO BENEFECIAMENTO DA BATATA E SEU EMPREGO NA OPERAÇÃO DE FLOCULAÇÃO NATURAL PARA TRATAMENTO DE EFLUENTES.
}

\author{
I.A. OLIVEIRA ${ }^{1}$, A. F. P. CAMPOS ${ }^{1}$ \\ ${ }^{1}$ Centro Universitário do Planalto de Araxá - UNIARAXÁ \\ E-mail para contato: anacampos@uniaraxa.edu.br
}

RESUMO - Nos últimos anos, os consumidores têm assumido um perfil de conveniência e praticidade, contribuindo para o desenvolvimento das indústrias alimentícias. Um exemplo, refere-se à batata, que tradicionalmente era comercializada in natura e têm ganhado significante espaço dentre os alimentos industrializados. Concomitante ao aumento de demanda da batata, verifica-se um aumento no volume de resíduos sólidos e líquidos gerados pelo seu processamento, responsáveis por expressivos danos ao meio ambiente. Em relação à sua composição nutricional, a batata é constituída essencialmente por água e carboidratos (amido). Dentre as várias propriedades funcionais do amido, sabe-se que esse possui excelente capacidade de formar flocos em solução. Baseados nessa característica e visando conciliar benefícios para as empresas processadoras e ao meio ambiente, este estudo teve como objetivo, o emprego do amido extraído da casca da batata, como floculante na estação de tratamento efluentes de uma indústria alimentícia processadora de batata, no município de Araxá - MG. Para a avaliação da eficiência do amido como floculante, diferentes quantidades desse foram adicionadas ao efluente. Adicionalmente, quantificou-se o teor de amido na entrada e na saída do processamento da batata, afim de verificar a viabilidade econômica dessa operação de floculação. Finalmente, comprovou-se a atividade do amido como floculante para remoção de sólidos suspensos presentes no efluente dessa indústria.

\section{INTRODUÇÃO}

A primeira indústria produtora de especialidades de batata no Brasil, encontra-se na cidade de Araxá - MG. Esta região é considerada a principal produtora de batata in natura do país, o que permite que em suas linhas de produção sejam utilizadas batatas frescas trazidas diretamente do campo para a indústria. As especialidades dessa empresa são produtos obtidos tanto do purê de batata quanto da batata ralada (SAVASSI, 2015).

Do ponto de vista ambiental, as atividades de uma indústria processadora de batata geram significantes quantidades de resíduos sólidos e líquidos (RESENDE, 2010). Em relação aos resíduos sólidos, destaca-se a casca da batata. Segundo Balsalobre (1995), no ano de 1995, aproximadamente 300 mil toneladas de casca de batata foram descartadas pelo segmento e o que se espera é que este valor aumente em função do progresso e dos hábitos de consumo da população. A casca da batata é um resíduo considerado de difícil manejo e reaproveitamento, devido ao seu elevado teor de umidade (LAUFENBERG; KUNZ; NYSTROEM, 2003).

A destinação inadequada de resíduos sólidos e líquidos pode implicar em degradações e contaminações expressivas dos solos e dos lençóis freáticos (principalmente por lixiviação) e consequentemente, na diminuição da disponibilidade dos recursos naturais (MOURA, 2002). 


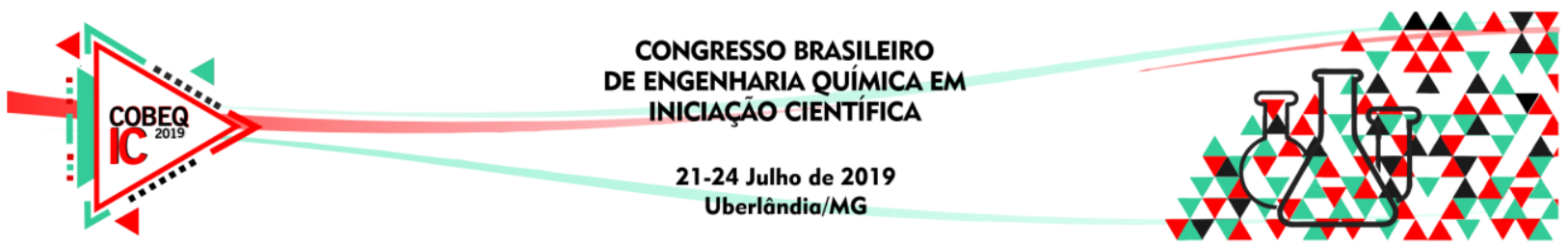

Adicionalmente, o lançamento de efluentes não tratados ao meio ambiente podem ocasionar a redução da concentração de oxigênio disponível, a diminuição da qualidade das águas e consequentemente o desequilíbrio de ecossistemas aquáticos e terrestres, a mortalidade de espécies e em casos mais graves, até mesmo sua extinção e eutrofização (ROCHA e colaboradores, 2004).

No que se refere à composição estrutural da batata, sabe-se que cerca de 65 a $80 \%$ de sua massa é constituída por carboidratos. Dentre estes carboidratos, destaca-se o amido. $\mathrm{O}$ amido é um homopolissacarídeo composto por dois polímeros, amilose e amilopectina. (TALBURT, SCHWIMMWER e BURR, 1975; PEREIRA, 1987). Dentre as diversas propriedades funcionais do amido, destaca-se sua excelente capacidade de se organizar em flóculos em solução. Sendo assim, uma das alternativas para tratamentos de águas residuárias, efluentes e esgotos é o emprego do amido durante o processo de floculação.

Campos e Netto (1980) utilizaram o amido na floculação para o tratamento de água, reduzindo consideravelmente os custos neste processo. Fagundes (2010) também adicionou o amido no tratamento de efluentes e analisou alguns parâmetros físico-químicos, tais como a turbidez e demanda química de oxigênio (DQO). Silva e Daniel (2010) sugerem que o amido pode ser um auxiliar de floculação de estações de tratamento de água, por promover principalmente a remoção da concentração de sólidos suspensos, ou seja, a remoção da turbidez.

Neste contexto, este estudo tem como principal objetivo avaliar a eficiência do amido proveniente da casca da batata ou seja, do rejeito dessa indústria, como floculante natural na estação de tratamento de efluentes da própria indústria alimentícia, situada no município de Araxá - MG. Entende-se que a obtenção de rendimentos consideráveis para a remoção de resíduos da Estação de Tratamento de Efluentes promoverá uma alternativa ambientalmente correta e economicamente viável, promovendo significantes benefícios para o meio ambiente e para a indústria processadora de batata.

\section{MATERIAIS E MÉTODOS}

\subsection{Extração de Amido}

A espécie de batata utilizada em todos os testes foi a Asterix, empregada durante toda a produção da indústria, que trabalha com duas linhas de produção, as quais se destinam à produtos à base do purê da batata (sem casca) e produtos à base da batata ralada (com percentual de casca). Para a matéria-prima à base de purê, obteve-se o teor de amido da polpa e da casca da batata, na entrada e saída dos processos.

Para quantificação do amido em escala laboratorial, primeiramente, convencionou-se utilizar 800 gramas da batata in natura ( 700 gramas de polpa e 100 gramas de casca). Para o rejeito da indústria, convencionou-se empregar uma massa de 800 gramas do mesmo. Após a pesagem de cada uma das matérias-primas, adicionou-se 0,15 gramas de bissulfito de sódio $\left(\mathrm{NaHSO}_{3}\right)$. O material obtido foi então triturado no liquidificador. Filtrou-se o fluido resultante em pano fino, manualmente. $\mathrm{O}$ bagaço foi descartado e o líquido coado permaneceu em repouso por uma hora. Após este tempo, verificou-se a formação de uma mistura heterogênea, contendo duas fases. A fase sobrenadante foi retirada. A fase mais densa, contendo o amido foi lavada com 150 a $250 \mathrm{ml}$ de álcool etílico (95\%). O amido obtido foi então submetido à estufa, sob temperatura e tempo de $60^{\circ} \mathrm{C}$ e 15 horas, respectivamente. Para extração do amido da casca e do rejeito da batata utilizou-se o mesmo procedimento. 


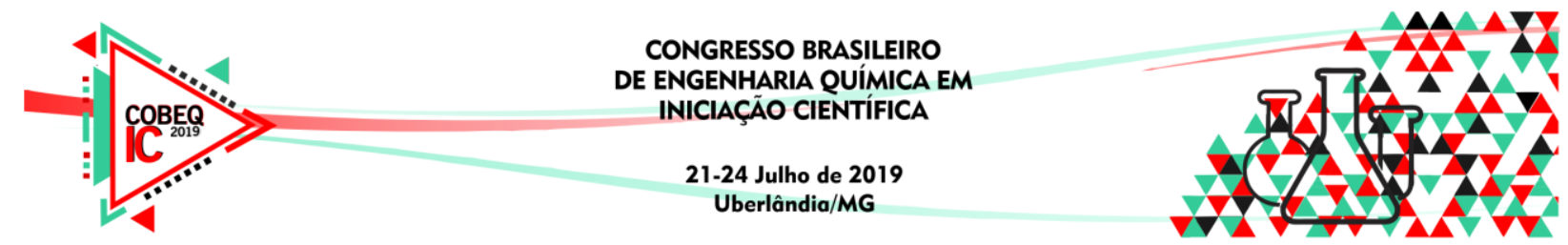

\subsection{Tratamento do Efluente Industrial}

Os testes de floculação com o amido do rejeito da batata foram realizados em triplicatas no equipamento Jartest, modelo 403 Alfakit, com amostras do efluente bruto da indústria sem qualquer tipo de tratamento. Cada jarro deste equipamento tem uma capacidade de 2 litros de efluente, o qual é capaz de promover uma agitação de moderada a rápida, permitindo a formação de flóculos. As quantidades de amido utilizadas foram 2,5, 5,0 e 7,5 gramas. Primeiramente, as amostras foram agitadas durante 10 minutos, sob agitação de $80 \mathrm{rpm}$ (rotações por minuto). Posteriormente, as amostras foram agitadas por mais 30 minutos, sob rotação de $40 \mathrm{rpm}$. Após a agitação, as amostras permaneceram em repouso por aproximadamente, 17 horas.

\subsection{Caracterização do efluente industrial}

Para caracterização do efluente industrial antes e após a etapa de floculação natural com o amido, determinou-se a quantidade de sólidos suspensos, através da turbidez, a quantidade de sólidos totais dissolvidos, através de medidas de condutividade e ainda o potencial hidrogeniônico $(\mathrm{pH})$. Para determinação da turbidez, utilizou-se um turbidimetro da marca MS TECNOPON, previamente calibrado. Para determinação dos sólidos dissolvidos, utilizouse um condutivímetro da marca HANNA, previamente calibrado.

\subsection{RESULTADOS E DISCUSSÕES}

\subsection{Influência do Bissulfito de Sódio $\left(\mathrm{NaHSO}_{3}\right)$ na extração de amido}

Neste estudo, o procedimento para a extração do amido da batata foi baseado no procedimento descrito por Pimenta (2017). De acordo com este autor, para que se obtenha uma extração eficiente do amido, é necessário adicionar $0,3 \%$ de bissulfito de sódio $\left(\mathrm{NaHSO}_{3}\right)$ para cada 1 litro de mistura, o que corresponde à aproximadamente, 4,4 gramas desta substância. Sendo assim, o primeiro objetivo deste estudo foi a avaliação da influência da quantidade de bissulfito de sódio na quantidade de amido extraída da batata, bem como, sua otimização na composição química para extração do amido.

Sendo assim, convencionou-se realizar a etapa de extração do amido da matéria-prima à base de "purê" com diferentes quantidades de bissulfito de sódio, como pode ser observado na Figura 1-a. Para a polpa, verifica-se que a maior quantidade de amido extraída foi obtida quando nenhuma quantidade de bissulfito de sódio foi adicionada à etapa de extração. Para as demais quantidades de bissulfito de sódio adicionadas, observa-se que a quantidade de amido extraída permaneceu constante. Para a casca, observa-se que as quantidades de amido extraídas quando nenhuma e 0,15 gramas de bissulfito de sódio foram adicionadas à mistura foram similares. A quantidade de amido extraída diminuiu quando foram adicionados 15 gramas de bissulfito de sódio. Em se tratando do rejeito, verifica-se que a adição de bissulfito de sódio à etapa de extração do amido não influenciou significantemente a quantidade de amido extraída, resultando em quantidades de amido extraídas próximas. 


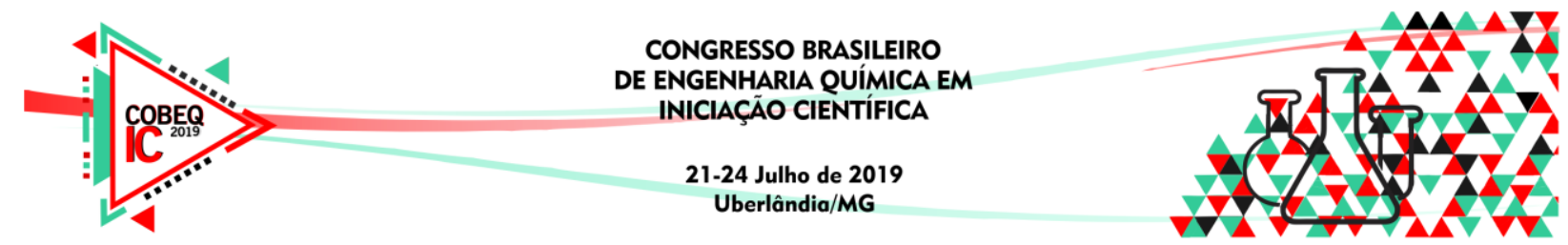

Figura 1 - (a) Quantidade de amido extraído (\%) em função da quantidade de bissulfito de sódio (gramas) na matéria-prima "purê". (b) Extração do amido com a presença e sem a presença de bissulfito de sódio.
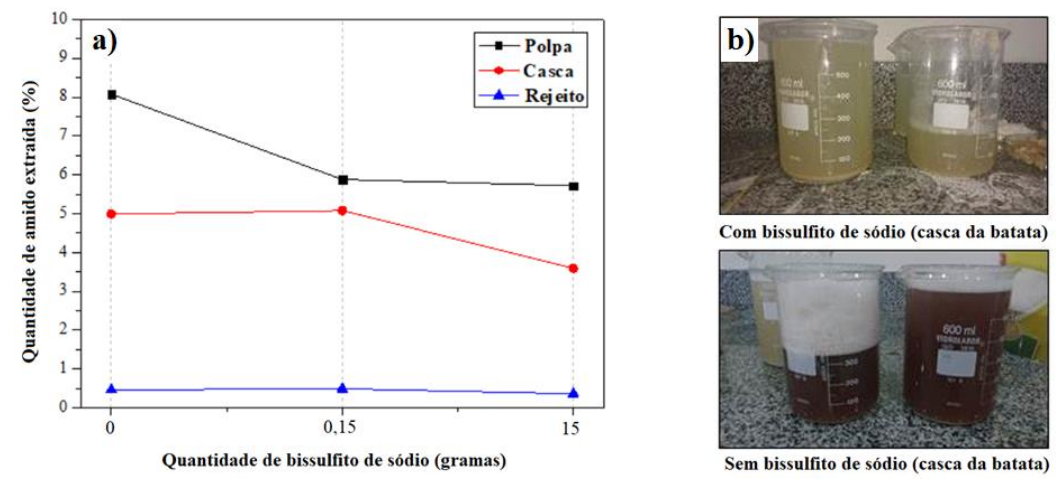

Outra questão referente à adição do bissulfito de sódio deve ser avaliada. Na Figura 1-b, pode-se observar uma mistura contendo casca de batata sem adição de bissulfito de sódio e com 15 gramas de bissulfito de sódio. Sem dúvidas, a diferença de coloração entre as misturas é aparente e essa diferença se deve ao fato de que o bissulfito de sódio é empregado como um sequestrante de oxigênio no tratamento de água, resultando na redução do potencial de oxidação de soluções (Bonifácio, 2015). O bissulfito de sódio possui a capacidade de retardar o escurecimento de materiais através do favorecimento do desprendimento de dióxido de enxofre na presença de água, que por sua vez, leva a morte das leveduras, fungos e bactérias, agindo assim, como um conservante (Nogueira, Pereira e Fakhouri, 2014)

Baseados nestes resultados, convencionou-se o emprego de 0,15 gramas de bissulfito de sódio para extração de amido de ambas as matérias-primas à base de purê. Estes resultados apresentam grande relevância, uma vez que, a diminuição da quantidade de bissulfito de sódio necessária para extração de amido resultará na redução dos custos dessa operação em larga escala.

Na Tabela 1, pode-se observar os valores percentuais médios de amido extraído da polpa, casca e no rejeito da batata, para os produtos com base de purê de batata. Baseados nestes resultados, em escala industrial, para cada dia de trabalho, são processadas, aproximadamente, 7500 quilos de batata in natura. Dessa massa de batata total alimentada à indústria, ao produzir produto com base de purê (sem casca), pode-se obter, 6.562,5 quilos de polpa e 937,5 quilos de casca. Da polpa e da casca, pode-se obter em torno de 306,5 e 28,1 quilos de amido, respectivamente. Comumente, descarta-se em torno de 4.000 quilos de rejeito. Neste rejeito, ocorre a incorporação alguns surfactantes até que o mesmo seja encaminhado para disposição final. A partir deste rejeito, por volta de 15,6 quilos é amido. Em resumo, para produto com base de purê, são alimentados, aproximadamente, 334,6 quilos de amido e deixam o processo através do rejeito, aproximadamente 15,6 quilos de amido.

Tabela 1 - Porcentagem média de amido extraído (\%) no produto a base de purê de batata.

\begin{tabular}{|c|c|}
\hline \multicolumn{2}{|c|}{ PORCENT AGEM MÉDIA DE AMIDO EXTRAÍDO (\%) } \\
\hline Matéria prima & Purê \\
\hline Polpa & 4,67 \\
\hline Casca & 3,0 \\
\hline Rejeito & 0,39 \\
\hline
\end{tabular}




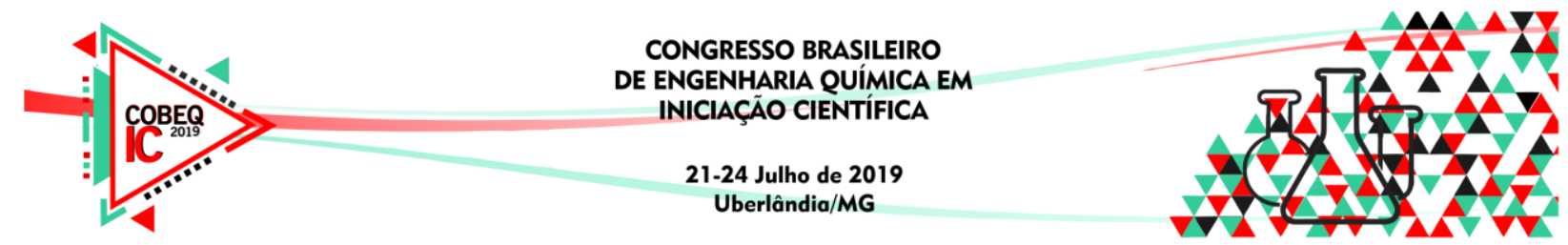

\subsection{Floculação com amido}

Após a determinação da quantidade do bissulfito de sódio ótima para extração do amido, avaliou-se a atividade de amido como floculante natural no tratamento do efluente obtido na indústria beneficiadora de batata. Os testes foram realizados empregando-se diferentes quantidades de amido (2,5, 5,0 e 7,5 gramas). Vale salientar que o efluente bruto da indústria beneficiadora de batata é constituído não apenas de casca de batata, mas também, água, amido, óleo vegetal e alguns produtos químicos necessários para a higienização da indústria. Por isso, optou-se por realizar operação de floculação sem o ajuste e com o ajuste do potencial hidrogeniônico $(\mathrm{pH})$. Para os testes realizados com controle de $\mathrm{pH}$, optou-se pelo valor de $\mathrm{pH}$ de 7,5, próximo a um valor de $\mathrm{pH}$ neutro. Para todos os testes, verificou-se que os valores do pH após a operação de floculação são inferiores a 7,0, o que caracteriza um efluente com características ácidas. Estes resultados já são esperados, uma vez que a batata possui $\mathrm{pH}$ próximo de 5,5. Adicionalmente, não descarta-se a possibilidade da presença de substancias químicas ácidas dispostas com o efluente que possam contribuir para a liberação de ions $\mathrm{H}^{+}$, contribuindo assim, para a diminuição dos valores do $\mathrm{pH}$.

A redução da turbidez de efluentes, segundo Fay e Silva (2006), auxilia na não desestabilização dos recursos hídricos, podendo evitar a redução do oxigênio dissolvido, a proliferação de toxinas e a eutrofização do ecossistema. Na Figura 2, tem-se os resultados da redução da turbidez, que está relacionada com a diminuição da quantidade de sólidos suspensos em função da quantidade de amido presente no efluente, sem e com controle de $\mathrm{pH}$. Naturalmente, a redução da turbidez aumenta com o aumento da quantidade de amido presente na operação de floculação para ambos os efluentes, sem e com ajuste de $\mathrm{pH}$. Para a operação de floculação realizada com 2,5 gramas de amido, a redução da turbidez passou de aproximadamente, $9 \%$ para $32 \%$ com o ajuste e sem o ajuste de $\mathrm{pH}$, respectivamente. Para as demais operações, realizadas com maiores quantidades de amido, verifica-se que o ajuste do pH do efluente não teve significativa influência na redução da turbidez do mesmo.

Figura 2 - Redução da turbidez (sólidos suspensos) (\%) em função da quantidade de amido (gramas), sem e com o ajuste de $\mathrm{pH}$.

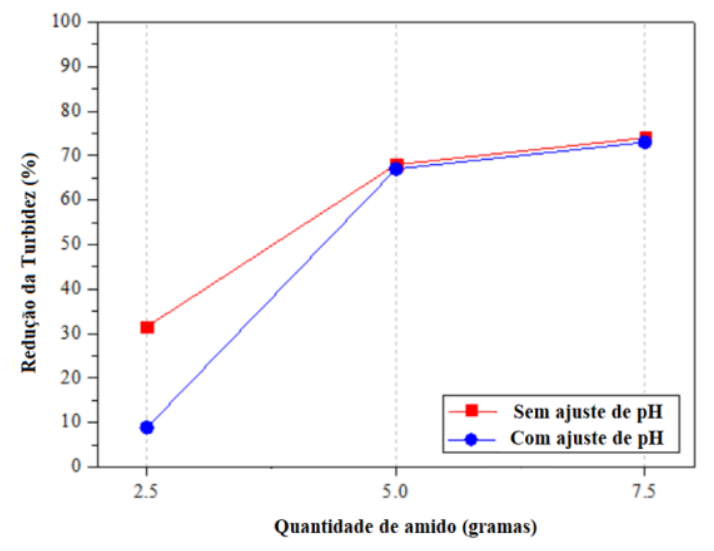

Tabela 2 - Quantidade de sólidos dissolvidos totais no efluente antes e após o processo de floculação com diferentes quantidades de amido.

\begin{tabular}{|c|c|c|}
\hline \multicolumn{3}{|c|}{ QUANTIDADE MÉDIA DE SÓLIDOS DISSOL VIDOS TOTAIS } \\
$\mathbf{( p p m )}$ \\
\hline \multicolumn{3}{|c|}{ Efluente sem ajuste de $\mathrm{pH}$} \\
\hline Quantidade de amido (gramas) & Antes & Depois \\
\hline 2,5 & 322 & 255 \\
\hline 5,0 & 440 & 379 \\
\hline 7,5 & 530 & 500 \\
\hline \multicolumn{2}{|c|}{ Efluente com ajuste de $\mathrm{pH}$} \\
\hline Quantidade de amido (gramas) & Antes & Depois \\
\hline 2,5 & 579 & 541 \\
\hline 5,0 & 552 & 893 \\
\hline 7,5 & 262 & 266 \\
\hline
\end{tabular}

Apesar da floculação ser entendida como sendo uma operação onde há a agregação de moléculas com dimensões entre $1 \mathrm{~nm}\left(10^{-9} \mathrm{~m}\right)$ e $1 \mu \mathrm{m}\left(10^{-6} \mathrm{~m}\right)$ que se separam da fase líquida em que estão suspensas (LIBÂNIO, 2010; PAVANELLI, 2001), avaliou-se o comportamento 


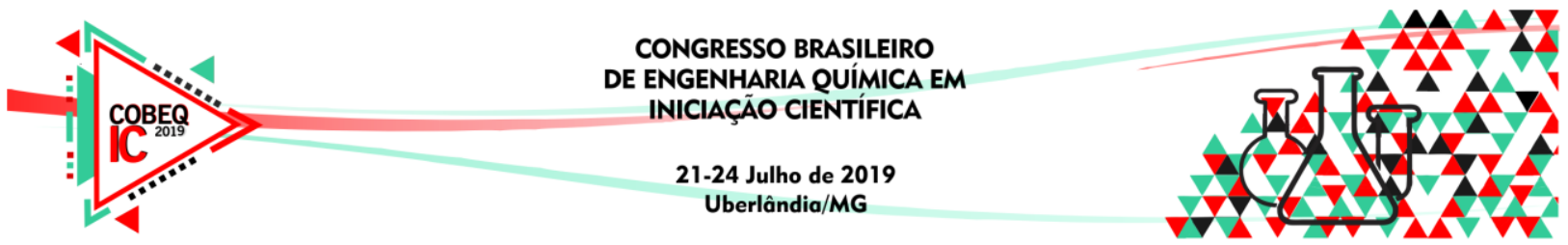

da quantidade de sólidos dissolvidos em função da quantidade de amido, como pode ser observado na Tabela 2. De acordo com os resultados, tem-se uma diminuição da quantidade de sólidos dissolvidos para todas as quantidades de amido empregadas na operação de floculação do efluente sem o ajuste de $\mathrm{pH}$. Para o efluente com o pH ajustado, verifica-se uma diminuição da quantidade de sólidos dissolvidos apenas para a operação de floculação contendo 2,5 gramas de amido. Para as demais quantidades de amido utilizadas, observa-se um aumento da quantidade dos sólidos dissolvidos.

\section{CONCLUSÕES}

Por meio deste estudo, primeiramente, além de comprovar a ação do bissulfito de sódio $\left(\mathrm{NaHSO}_{3}\right)$, como agente antioxidante, pode-se otimizar sua quantidade na composição química para extração do amido, para apenas 0,15 gramas. Após a determinação ótima de bissulfito de sódio necessária para a extração do amido da batata, foi possível extrair o amido da polpa, casca e rejeito do produtos da indústria com base de purê. Através destes resultados pode-se estimar as quantidades de amido que entram e saem o processo de beneficiamento industrial.

Em relação à operação de floculação com diferentes quantidades de amido, verificou-se que a quantidade de amido presente na mistura e a diminuição da quantidade de sólidos suspensos são diretamente proporcionais, com o ajuste ou não do $\mathrm{pH}$ da mistura. Em alguns casos, observou-se ainda a diminuição dos sólidos dissolvidos presentes nos efluentes.

Acredita-se que a operação de floculação com amido possa ser vinculada ao tratamento biológico, atualmente utilizado pela indústria, ou ainda, ser a operação principal para tratamento dos efluentes desta indústria, uma vez que, para o tratamento de 380 litros de efluente seriam necessários apenas 1,425 quilos de amido do rejeito para se conseguir a mesma eficiência do processo biológico. Finalmente, pode-se considerar que a operação de floculação com amido extraído do rejeito da indústria beneficiadora da batata é uma promissora operação para tratamento de efluentes desta natureza, além de ser uma operação ambientalmente correta e economicamente viável.

\section{REFERÊNCIAS}

BALSALOBRE, M. A. A. Batata, beterraba, cenoura e nabo. In: SIMPÓSIO SOBRE NUTRIÇÃO DE BOVINOS, 6. 1995, Piracicaba. Anais.Piracicaba, 1995. p. 99-121.

BONIFÁCIO, Pedro Lúcio. "Equilíbrio Líquido-Líquido em Misturas de Polietienoglicol ( 4.000 ou 6.000 ou 10.000 g mol-1 )+ Bissulfito de Sódio + Água em Diferentes Temperaturas”. 2015. 56 f. Dissertação (Mestrado) - Curso de Química, Universidade Federal de Alfenas, Alfenas, 2015.

CAMPOS, José Roberto; NETTO, José Martiniano de Azevedo. Emprego de amido de batata como auxiliar de floculação de águas para abastecimento. Revista Dae, La Paz - Bolívia, p.30-38, 1980.

FAGUNDES, Thalita Salgado. Uso do polímero natural a base de amido como auxiliar de floculação no pós-tratamento de efluentes UASB por flotação por ar dissolvido. 2010. 111 f. TCC (Graduação) - Curso de Engenharia Ambiental, Universidade de São Paulo, São Carlos, 2010.

FAY, E. F.; SILVA, C. M. M. S. Índice de uso sustentável da água (ISA - Água) na região do sub - médio São Francisco. 1. ed. Jaguariúna: Embrapa Meio Ambiente, 2006.p. 157.

LAUFENBERG, G.; KUNZ, B.; NYSTROEM, M. Transformation of vegetable waste into added products: (A) the upgrading concept; (B) practical implementations. Bioresource Technology, Londres, v. 87, n. 2, p. 167-198, 2003

LIBÂNIO, M. Fundamentos de qualidade e tratamento de água. Campinas: Átomo, 2010.

MOURA, L. A. A. Qualidade e Gestão Ambiental. 3. ed. São Paulo: Juarez de Oliveira, 2002.

NOGUEIRA, T. Y. K.; PEREIRA, A. D.; FAKHOURI, F. M. Extração e caracterização do amido de araruta. In: ENCONTRO DE ENSINO, PESQUISA E EXTENSÃO, 8., 2014, Dourados. Anais... Dourados: ENEPE-UFGD, 2014. p. 1-15.

PIMENTA, Carlos José et al. Extração do amido em diferentes cereais. Lavras: Universidade Federal de Lavras, 2017. 10 p.

RESENDE, Domingos Sávio de. Caracterização de resíduos sólidos de estação de tratamento de esgoto da indústria de batatas e avaliação como adição para a produção de compósitos cimentícios. 2010. 116 f. Dissertação (Mestrado) - Curso de Engenharia de Materiais, Ufop, Ouro Preto, 2010.

ROCHA, M.M.; SARTI,H.L.C.;LIMA,L.F.;JUNIOR,O.C. A urbanização e poluição dos recursos hídricos. O Mundo da Saúde.v.28,n.4,p.388-394,2004

SAVASSI, Jornal. Forno de Minas associa-se a Sérya alimentos para atuar no segmento de especialidade de batatas congeladas. 2015.

SILVA, D. R.; DANIEL, L. A. Aproveitamento de lodos gerados em ETAs e a importância de auxiliares de floculação naturais. Revista Dae, [s.l.], v. 58, n. 183, p.21-24, 2010. Editora Cubo Multimidia. TALBURT, W. F.; SCHWIMMWER, S.; BURR, H. K. Structure and chemical composition of the potato tuber. In: TALBURT, W. F.; SMITH, O. Potato processing. Westport: AVI, 1975. p. 11-42. 